\title{
Determinants of Pancreatic Steatosis: A Retrospective Observational Study
}

\author{
Emre Altinmakas ${ }^{1}$, Begum Guler ${ }^{2}$, Sidar Copur ${ }^{2}$, Dimitrie Siriopol ${ }^{3}$, Alan A. Sag ${ }^{4}$ Serkan Guneyli ${ }^{1}$, \\ Hakan Dogan ${ }^{1}$, Baris Afsar ${ }^{5}$ Emre Balik ${ }^{6}$, Adrian Covic ${ }^{3}$, Richard J. Johnson ${ }^{7}$, Mehmet Kanbay 8,*
}

1. Department of Radiology, Koc University School of Medicine, Istanbul, Turkey.

2. Department of Medicine, Koc University School of Medicine, Istanbul, Turkey.

3. Nephrology Clinic, Dialysis and Renal Transplant Center, 'C.I. PARHON' University Hospital, and 'Grigore T. Popa' University of Medicine, Iasi, Romania.

4. Division of Vascular and Interventional Radiology, Department of Radiology, Duke University Medical Center, Durham, USA.

5. Department of Medicine, Division of Nephrology, Suleyman Demirel University School of Medicine, Isparta, Turkey.

6. Department of General Surgery, Koc University School of Medicine, Istanbul, Turkey.

7. Division of Renal Diseases and Hypertension, School of Medicine, University of Colorado Denver, Aurora, CO, USA.

8. Department of Medicine, Division of Nephrology, Koc University School of Medicine, Istanbul, Turkey

\section{Corresponding Author:}

NMehmet Kanbay, MD

Department of Medicine, Division of Nephrology Koc University School of Medicine 34010, Istanbul, Turkey

Tel: +902122508250

Fax: + 908502508250

E-mail: mkanbay@ku.edu.tr

Received : 24 Nov. 2020

Accepted : 04 Apr. 2021

\section{ABSTRACT}

\section{BACKGROUND}

Metabolic syndrome affects $35 \%$ of the adult population in developed countries associated with non-alcoholic steatohepatitis, insulin resistance, and cardiovascular events. Fatty infiltration of the pancreas, or pancreatic steatosis, is a risk factor for acute pancreatitis, pancreatic malignancies, and diabetes mellitus, yet its relationship with metabolic syndrome is not well defined.

\section{METHODS}

We performed a single-centered retrospective observational study of 322 healthy subjects (subjects volunteering to be kidney transplant donors, mean age $=46.3 \pm 13.5$, 163 men and 159 women) in the last 2 years (July 2018-February 2020) from our institution. Pancreatic steatosis and hepatosteatosis were confirmed by computed tomography.

\section{RESULTS}

Pancreatic steatosis was present in $26.3 \%$ (85/322) of the subjects, and this finding correlated with age, body mass index (BMI), male sex, a family history of diabetes, creatinine, cystatin C, uric acid, low-density lipoprotein (LDL) cholesterol, triglycerides, glycemia, hemoglobin, transverse body diameter, and subcutaneous fat thickness levels by univariable logistic regression. On multiple linear regression only age (95\% CI 1.01, 1.06), BMI (95\% CI 1.01, 1.19), male sex (95\% CI 1.49-5.99), uric acid $(95 \%$ CI 1.01, 1.76), and subcutaneous fat thickness levels (95\% CI 1.21-2.36) remained independently associated with pancreatic steatosis.

\section{CONCLUSION}

Pancreatic steatosis is common and associated with obesity, elevated serum uric acid, subcutaneous fat thickness, and male sex. Future studies are needed to evaluate if there are specific clinical consequences to the presence of pancreatic steatosis.

\section{KEYWORDS:}

Visceral steatosis, Uric acid, Liver steatosis, Obesity

Please cite this paper as:

Altinmakas E, Guler B, Copur S, Siriopol D, A. Sag A, Guneyli S, Dogan H, Afsar B, Balik E, Covic A, J. Johnson R, Kanbay M. Determinants of Pancreatic Steatosis: A Retrospective Observational Study. Middle East J Dig Dis 2021;13: 343-349. doi: 10.34172/ mejdd. 2021.245 


\section{INTRODUCTION}

Metabolic syndrome is considered a medical pandemic that affects approximately $35 \%$ of the adult population in western countries leading to significant comorbidities including diabetes mellitus, pro-thrombotic and proinflammatory state, cardiovascular events, and non-alcoholic fatty liver disease (NAFLD). ${ }^{1,2}$ As the global incidence of metabolic syndrome is on the rise, the associated comorbidities gain importance, among which pancreatic steatosis is a newly recognized concept. ${ }^{3}$ Cadaveric studies performed by Ogilvie in 1933 indicated higher pancreatic fat $(17 \%)$ in obese cadavers compared with lean cadavers $(9 \%)$, while a limited number of radiological studies demonstrated a similar correlation. ${ }^{4-7}$ Additionally, a few studies noted a frequent coexistence of NAFLD and pancreatic steatosis, ${ }^{8-10}$ while others reported the correlation of pancreatic steatosis with the severity of acute pancreatitis. ${ }^{11,12}$ Fatty infiltration of the liver and other tissues has been linked to an increase in the production of certain adipokines such as leptin and adiponectin and of different proinflammatory cytokines such as tumor necrosis factoralpha, interleukin-6, interleukin-1 $\beta$ myeloperoxidase, and monocyte chemotactic protein-1. ${ }^{13-15}$ Although animal studies demonstrated a link between fatty pancreatic infiltration and beta-cell dysfunction, human studies revealed contradictory findings regarding the emergence of insulin resistance or diabetes mellitus. ${ }^{16-19}$ There is a need for more studies for identifying risk factors and comorbidities associated with pancreatic steatosis since early detection and intervention, such as caloric restriction and weight loss, have been shown to reverse the condition. ${ }^{20}$

Here we performed a single-center retrospective study to determine the association between pancreatic steatosis assessed via imaging studies and laboratory and clinical features in a cohort of healthy participants.

\section{MATERIALS AND METHODS}

\section{Study Design:}

We performed a single-center retrospective observational study including all 327 healthy renal transplantation donors in the last 2 years (July 2018-February 2020) from our institution. The study was approved by the Eth- ics Committee of the Koc University School of Medicine. Baseline laboratory values of the patients included kidney function tests (serum creatinine, estimated glomerular filtration rate (eGFR), cystatin C), liver function tests (alanine aminotransferase (ALT), aspartate aminotransferase (AST), direct and total bilirubin, alkaline phosphatase (ALP)), uric acid, complete blood count, 24-hour proteinuria, spot urine albumin-creatinine ratio, fasting glucose, triglycerides, high-density lipoprotein (HDL), low-density lipoprotein (LDL), and thyroid-stimulating hormone were recorded. Additionally, family history (i.e. cardiovascular disease, chronic disease, chronic liver disease, and diabetes mellitus), physical measurements (i.e. body mass index [BMI], systolic and diastolic blood pressure) and social features of the participants (i.e. smoking and alcohol consumption) were recorded. Computed tomography (CT) scans were employed to assess transverse body diameter, subcutaneous fat thickness, and hepatic and pancreatic steatosis. Details of the radiological process can be accessed in the following section. We excluded five participants with inadequate laboratory and imaging data.

\section{Imaging Analysis:}

All images were performed on a Siemens CT scanner, either 64-slice (Somatom) or 256-slice (Definition Flash). Unenhanced axial CT images at 2-mm slice thickness and $\mathrm{kVp}$ values ranging between $80-140 \mathrm{kVp}$ were used. All images were reviewed by one of two radiologists (E.A. and S.G.) with over 10 years of experience in reading abdominal $\mathrm{CT}$.

Measurements were performed on an independent General Electric workstation. Three regions of interest (ROIs) were drawn on the right and left lobes of the liver and spleen (upper/middle/lower pole). To ensure reproducibility of the measurements, the ROIs were drawn to avoid vessels, focal lesions, and parenchymal calcifications. The density values were noted in Hounsfield Unit (HU). Data were tabulated into Microsoft Excel and means calculated thereof.

Hepatic steatosis was defined as a mean hepatic density at least 5 HU less than the mean splenic density ("severe" if the difference exceeded $10 \mathrm{HU}$, otherwise "mild-to-moderate"). ${ }^{21}$

Similarly, five different ROIs were drawn in the unci- 
nate process, head, neck, body, and tail of the pancreas. Densities were tabulated and means calculated as above. Pancreatic steatosis was defined as "present" if the mean pancreatic density was at least $5 \mathrm{HU}$ less than that of the spleen. ${ }^{22}$ The widest axial abdominal diameter was measured. Axial subcutaneous fat thickness was always measured in the anterior-to-posterior direction at the periumbilical region. Psoas muscle cross-section area was measured using free-hand ROI at the level of L3.

\section{Statistical analysis:}

Variables were expressed as median with interquartile range, mean \pm standard deviation or as percent frequency, as appropriate. Between-groups comparisons were assessed for nominal variables with the Chi-square or Fisher's tests and by independent-samples t test or Mann-Whitney test for the rest of the variables. The distribution of the variables was assessed using the ShapiroWilk test.

Logistic regression analysis was used to assess the variables associated with pancreatic steatosis. Those variables with $\mathrm{p}<0.05$ by univariate analysis were included in the backward stepwise multivariate logistic regression analysis model, and the respective odds ratios (ORs) with 95\% confidence intervals (CIs) were determined.

All analyses were performed using Stata MP software, version 13 (Stata Statistical Software: Release 13. College Station, TX: StataCorp LP.). A two-tailed $\mathrm{p}<0.05$ was considered to be significant.

\section{RESULTS}

\section{Patient Demographics}

322 patients were included. The mean age was $46.3 \pm 13.5$ years. 163 patients $(50.6 \%)$ were men, and $126(39.1 \%)$ were active smokers. Other clinical and biological characteristics of the subjects are presented in table 1 .

We divided the patients into two groups based on the presence of pancreatic steatosis (table 1). Patients with this pathology were older, had higher BMI values, and were more likely to be men, have a family history of diabetes and hepatic steatosis. Furthermore, these patients also had higher creatinine, cystatin $\mathrm{C}$, uric acid, LDL cholesterol, triglycerides, hyperglycemia, ALT, hemoglobin, transverse body diameter, and subcutaneous fat thickness levels but lower eGFR values than patients without pancreatic steatosis (table 1). Univariate logistic regression analysis demonstrated a positive correlation with age, BMI, male sex, a family history of diabetes, creatinine, cystatin C, uric acid, LDL cholesterol, triglycerides, glycemia, ALT, hemoglobin, transverse body diameter, and subcutaneous fat thickness levels, and negatively associated with eGFR (table 2).

In a multiple linear regression model, including all these predictors of pancreatic steatosis, only age, BMI, male sex, uric acid, and subcutaneous fat thickness levels remained independently associated with pancreatic steatosis.

\section{DISCUSSION}

We demonstrated an independent association between age, BMI, male sex, uric acid, subcutaneous fat thickness, and pancreatic steatosis in our single-center retrospective observational study that included 322 healthy participants The primary finding was that pancreatic steatosis appears to be a part of the constellation of findings associated with metabolic syndrome as well as age. Prior studies have correlated pancreatic steatosis with age. ${ }^{17,23-25}$ and BMI, ${ }^{16,24,26}$ while being inconclusive for serum lipid profile, ${ }^{16,22,25,27}$ visceral adipose tissue, ${ }^{24-27}$ beta-cell function. ${ }^{16,22,24,26,28-30}$ liver function tests, ${ }^{8-10,22}$ and uric acid. ${ }^{31,32}$ Here we identified elevated serum uric acid and subcutaneous fat thickness as independent risk factors for pancreatic steatosis. Although in the univariable analysis, we observed a relationship between pancreatic steatosis and renal function (as assessed by either serum creatinine, cystatin $\mathrm{C}$, or eGFR), in the multivariable analysis, this association was lost. Thus, our study is important by showing that in healthy people, there is no association between kidney function and pancreatic fat infiltration. The role of uric acid as an independent risk factor for pancreatic steatosis, although the renal function is not, raises further questions regarding the indirect role of uric acid in the pathophysiology that may be related to a chronic inflammatory state, insulin resistance, hepatosteatosis, and vascular dysfunction associated with hyperuricemia. ${ }^{33-35}$

In the diagnosis of pancreatic steatosis, $\mathrm{CT}$ is the most commonly used imaging modality in the literature. In a study comparing unenhanced CT density of the pancreas and histopathology, Kim and colleagues found that the histologic pancreatic fat fraction was significantly correlated with the 
Table 1: Baseline characteristics of the study population.

\begin{tabular}{|c|c|c|c|c|}
\hline Variables & All $(N=322)$ & No steatosis $(\mathrm{N}=\mathbf{2 3 7})$ & With Steatosis $(\mathbf{N}=\mathbf{8 5})$ & $\mathrm{p}$ \\
\hline Age, years & $46.3 \pm 13.5$ & $44.4 \pm 13.0$ & $51.5 \pm 13.5$ & $<0.001$ \\
\hline BMI, $\mathrm{kg} / \mathrm{m}^{2}$ & $26.6 \pm 4.3$ & $25.8 \pm 3.9$ & $28.7 \pm 4.4$ & $<0.001$ \\
\hline Male, n (\%) & $163(50.6)$ & $107(45.2)$ & $56(65.9)$ & 0.001 \\
\hline Smoking, n (\%) & $126(39.1)$ & $91(38.4)$ & $35(41.2)$ & 0.65 \\
\hline Alcohol consumption, $\mathrm{n}(\%)$ & $42(13.0)$ & $31(13.1)$ & $11(12.9)$ & 0.97 \\
\hline Family history of diabetes, $\mathrm{n}(\%)$ & $85(26.4)$ & $53(22.4)$ & $32(37.7)$ & 0.01 \\
\hline Family history of CVD, n (\%) & $51(15.8)$ & $40(16.9)$ & $11(12.9)$ & 0.39 \\
\hline SBP, mmHg & $117.1 \pm 9.0$ & $116.5 \pm 8.9$ & $118.7 \pm 9.3$ & 0.06 \\
\hline DBP, mmHg & $74.6 \pm 7.8$ & $74.5 \pm 7.8$ & $74.8 \pm 7.8$ & 0.79 \\
\hline Creatinine, $\mathrm{mg} / \mathrm{dL}$ & $0.79 \pm 0.16$ & $0.78 \pm 0.16$ & $0.84 \pm 0.15$ & 0.01 \\
\hline Cystatin C, mg/L & $0.87 \pm 0.16$ & $0.85 \pm 0.15$ & $0.94 \pm 0.18$ & $<0.001$ \\
\hline $\mathrm{eGFR}, \mathrm{ml} / \mathrm{min} / 1.73 \mathrm{~m}^{2}$ & $107.9 \pm 23.2$ & $110.1 \pm 22.2$ & $101.6 \pm 24.9$ & 0.004 \\
\hline Uric acid, mg/dL & $4.7(4.0-5.8)$ & $4.5(3.8-5.4)$ & $5.9(4.4-6.5)$ & $<0.001$ \\
\hline Serum albumin, g/dL & $4.65 \pm 0.29$ & $4.64 \pm 0.29$ & $4.68 \pm 0.26$ & 0.21 \\
\hline Total cholesterol, mg/dL & $187.0(160.0-219.0)$ & $185.0(158.0-215.0)$ & $197.0(164.0-226.0)$ & 0.06 \\
\hline HDL cholesterol, mg/dL & $49.0(41.0-59.0)$ & $50.0(41.0-60.0)$ & $45.0(39.0-56.0)$ & 0.06 \\
\hline LDL cholesterol, mg/dL & $130.0(102.0-157.0)$ & $124.0(101.0-151.0)$ & $138.0(110.0-164.0)$ & 0.01 \\
\hline Triglycerides, mg/dL & $106.0(77.0-149.0)$ & $104.0(76.0-143.0)$ & $124.0(96.0-154.0)$ & 0.01 \\
\hline Glycemia, mg/dL & $95.4 \pm 6.7$ & $94.9 \pm 6.8$ & $96.9 \pm 6.3$ & 0.02 \\
\hline ALT, U/L & $15.0(11.0-20.0)$ & $15.0(11.0-19.0)$ & $17.0(14.0-25.0)$ & 0.003 \\
\hline AST, U/L & $16.0(14.0-20.0)$ & $16.0(13.0-19.0)$ & $16.0(15.0-20.0)$ & 0.06 \\
\hline ALP, IU/L & $70.0(57.0-86.0)$ & $68.0(56.0-85.0)$ & $74.0(62.0-87.0)$ & 0.09 \\
\hline Total bilirubin, $\mathrm{mg} / \mathrm{dL}$ & $0.47(0.30-0.64)$ & $0.47(0.30-0.64)$ & $0.47(0.30-0.63)$ & 0.89 \\
\hline Direct bilirubin, $\mathrm{mg} / \mathrm{dL}$ & $0.20(0.15-0.26)$ & $0.20(0.15-0.26)$ & $0.20(0.16-0.27)$ & 0.68 \\
\hline $\mathrm{WBC}, * 10^{3} / \mathrm{mm}^{3}$ & $7.4 \pm 1.9$ & $7.3 \pm 1.9$ & $7.7 \pm 1.9$ & 0.13 \\
\hline Hemoglobin, $g / d L$ & $13.8 \pm 1.6$ & $13.7 \pm 1.6$ & $14.2 \pm 1.5$ & 0.01 \\
\hline Platelets, $* 10^{3} / \mathrm{mm}^{3}$ & $254.5(221.0-292.0)$ & $253.0(219.0-293.0)$ & $256.0(231.0-288.0)$ & 0.71 \\
\hline TSH, mIU/L & $1.7(1.2-2.5)$ & $1.7(1.1-2.5)$ & $1.8(1.3-2.3)$ & 0.50 \\
\hline UACR, $\mathrm{mg} / \mathrm{g}$ & $4.9(2.9-12.7)$ & $4.9(2.9-10.0)$ & $5.0(2.9-26.2)$ & 0.12 \\
\hline 24-hour proteinuria, $\mathrm{mg}$ /day & $108.1(88.0-134.6)$ & $109.0(88.0-132.2)$ & $107.8(87.3-144.9)$ & 0.84 \\
\hline Transverse body diameter, $\mathrm{cm}$ & $34.5 \pm 3.9$ & $33.7 \pm 4.0$ & $36.6 \pm 2.9$ & $<0.001$ \\
\hline Subcutaneous fat thickness, $\mathrm{cm}$ & $2.7 \pm 1.1$ & $2.5 \pm 1.1$ & $3.2 \pm 1.0$ & $<0.001$ \\
\hline \multicolumn{5}{|l|}{ Hepatic steatosis, n (\%) } \\
\hline Severe steatosis & $9(2.8)$ & $5(2.1)$ & $4(4.7)$ & \multirow{3}{*}{$<0.001$} \\
\hline Moderate steatosis & $43(13.4)$ & $21(8.9)$ & $22(25.9)$ & \\
\hline No steatosis & $270(83.9)$ & $211(89.0)$ & $59(69.4)$ & \\
\hline
\end{tabular}

Data are expressed as mean $\pm \mathrm{SD}$, median with IQR, or percent frequency, as appropriate.

UACR - urinary albumin to creatinine ratio; ALP - alkaline phosphatase; ALT - alanine transaminase; AST - aspartate transaminase; BMI - body mass index; CVD - cardiovascular disease; DBP - diastolic blood pressure; eGFR - estimated glomerular filtration rate; HDL - high-density lipoprotein; LDL - low-density lipoprotein; SBP - systolic blood pressure; TSH - thyroid-stimulating hormone ; WBC - white blood cells. 
Table 2: Univariable and multivariate logistic regression

\begin{tabular}{lll}
\hline Univariable analysis & OR & $\mathbf{9 5 \%}$ CI \\
\hline Age, per 1 year increase & 1.04 & $1.02-1.06$ \\
\hline BMI, per $1 \mathrm{~kg} / \mathrm{m}^{2}$ increase & 1.19 & $1.11-1.27$ \\
\hline Sex (Ref. Female) & 2.35 & $1.40-3.93$ \\
\hline Family history of diabetes (Ref. No history) & 2.09 & $1.23-3.58$ \\
\hline Glycemia, per $1 \mathrm{mg} / \mathrm{dL}$ increase & 1.05 & $1.01-1.09$ \\
\hline Creatinine, per $1 \mathrm{mg} / \mathrm{dL}$ increase & 8.91 & $1.87-42.49$ \\
\hline Cystatin C, per $1 \mathrm{mg} / \mathrm{L}$ increase & 31.50 & $6.47-153.34$ \\
\hline eGFR, per $1 \mathrm{ml} / \mathrm{min} / 1.73 \mathrm{~m}{ }^{2}$ increase & 0.98 & $0.97-0.99$ \\
\hline Hemoglobin, per $1 \mathrm{~g} / \mathrm{dL}$ increase & 1.24 & $1.06-1.46$ \\
\hline Uric acid, per $1 \mathrm{mg} / \mathrm{dL}$ increase & 1.88 & $1.51-2.35$ \\
\hline LDL cholesterol, per $10 \mathrm{mg} / \mathrm{dL}$ increase & 1.07 & $1.01-1.14$ \\
\hline ALT, per 10 U/L increase & 1.31 & $1.05-1.65$ \\
\hline Transverse body diameter, per $1 \mathrm{~cm}$ increase & 1.24 & $1.15-1.34$ \\
\hline Subcutaneous fat thickness, per $1 \mathrm{~cm}$ increase & 1.88 & $1.46-2.43$ \\
\hline Hepatic steatosis (Ref. No hepatic steatosis) & 3.58 & $1.93-6.62$ \\
\hline
\end{tabular}

\begin{tabular}{lll}
\hline Multivariable analysis & OR & $\mathbf{9 5 \%}$ CI \\
\hline Age, per 1 year increase & 1.04 & $1.01-1.06$ \\
\hline BMI, per $1 \mathrm{~kg} / \mathrm{m}^{2}$ increase & 1.10 & $1.01-1.19$ \\
\hline Sex (Ref. Female) & 2.99 & $1.49-5.99$ \\
\hline Uric acid, per $1 \mathrm{mg} / \mathrm{dL}$ increase & 1.33 & $1.01-1.76$ \\
\hline Subcutaneous fat thickness, per $1 \mathrm{~cm}$ increase & 1.69 & $1.21-2.36$ \\
\hline
\end{tabular}

(ALT - alanine transaminase; BMI - body mass index; eGFR - estimated glomerular filtration rate; LDL - low-density lipoprotein)

difference between pancreatic and splenic attenuation. ${ }^{36}$ In this study, sensitivity and specificity of pancreatic steatosis were found $79.3 \%$ and $42.4 \%$, respectively. Another study investigating the correlation between pancreatic steatosis and metabolic syndrome also used unenhanced $\mathrm{CT}$ as the reference standard. ${ }^{21}$ In this study, $-5 \mathrm{HU}$ was used as a cutoff for and pancreatic steatosis values less than -5 HU was considered as the fatty pancreas. In our study, we applied the same cutoff to our cohort. In order to increase the accuracy of density measurements, as much as pancreatic and splenic tissue were included. Therefore, multiple ROIs were drawn in all anatomical segments of the pancreas as well as the spleen, which was described in the methods section.

Our study provides new data on the prevalence and risk factors of pancreatic steatosis in participants with no preexisting medical condition. The limitations of our analysis include being a single-center retrospective study and also being unable to identify long-term outcomes of such associations. As pancreatic steatosis has been shown as a risk factor for certain medical conditions, like acute pancreatitis, diabetes mellitus, or non-alcoholic steatohepatitis and also that earlier intervention is likely to reverse the condition, identification of high-risk patients could have great significance in preventive medicine.

In conclusion, pancreatic steatosis is a common finding and associated with obesity, serum uric acid, subcutaneous fat thickness, and sex. Future large-scale prospective studies are needed for more comprehensive identification of the importance of pancreatic steatosis on the development of systemic disease.

Significance of this study:

- Pancreatic steatosis is a common finding. 
- $\quad$ Pancreatic steatosis is associated with obesity, serum uric acid, subcutaneous fat thickness and gender.

- $\quad$ Future large scale prospective studies are needed for more comprehensive identification of the importance of pancreatic steatosis on development of systemic disease

\section{ACKNOWLEDGMENTS:}

MK gratefully acknowledges the use of the services and facilities of the Koç University Research Center for Translational Medicine (KUTTAM), funded by the Presidency of Turkey, Presidency of Strategy and Budget. The content is solely the responsibility of the authors and does not necessarily represent the official views of the Presidency of Strategy and Budget."

\section{Contribution of authors:}

- Contributed substantially to the conception or design of the work; or the acquisition, analysis, or interpretation of data for the work: Emre Altinmakas Begum Guler Sidar Copur Serkan Guneyli Hakan Dogan Baris Afsar, Mehmet Kanbay

- Drafted the work or revised it critically for important intellectual content: Dimitrie Siriopol Alan Sag, Alan A. Sag Emre Balik Masanari Kuwabara, Adrian Covic, Mehmet Kanbay

- $\quad$ Approved the final version to be published: Adrian Covic, Alberto Ortiz, Masanari Kuwabara Richard J. Johnson, Mehmet Kanbay

\section{Compliance with Ethical Standards: \\ Financial Disclosure: None}

\section{ETHICAL APPROVAL}

There is nothing to be declared.

\section{CONFLICT OF INTEREST}

The authors declare no conflict of interest related to this work.

\section{REFERENCES}

1. Cornier M-A, Dabelea D, Hernandez TL, Lindstrom RC, Steig AJ, Stob NR, et al. The metabolic syndrome. Endocr Rev 2008;29:777-822. doi: 10.1210/er.2008-0024

2. Kanbay M, Jensen T, Solak Y, Le M, Roncal-Jimenez C, Rivard C, et al. Uric acid in metabolic syndrome: From an innocent bystander to a central player. Eur J Intern
Med 2016;29:3-8. doi: 10.1016/j.ejim.2015.11.026

3. MathurA, Marine M, LuD, Swartz-Basile DA, Saxena R, Zyromski NJ, et al. Non-alcoholic fatty pancreas disease. $H P B$ (Oxford). 2007;9:312-8. doi: 10.1080/13651820701504157

4. Ogilvie RF. The islands of Langerhans in 19 cases of obesity. J Pathol Bacteriol 1933;37:473-81. doi: 10.1002/ path. 17003703145.

5. Katz D, Hines J, Math K, Nardi P, Mindelzun R, Lane M. Using CT to reveal fat-containing abnormalities of the pancreas. AJR Am J Roentgenol 1999;172:393-6. doi: 10.2214/ajr.172.2.9930790

6. Matsumoto S, Mori H, Miyake H, Takaki H, Maeda T, Yamada Y, et al. Uneven fatty replacement of the pancreas: evaluation with CT. Radiology 1995;194:453-8. doi: 10.1148/radiology.194.2.7824726.

7. Kovanlikaya A, Mittelman SD, Ward A, Geffner ME, Dorey $\mathrm{F}$, Gilsanz V. Obesity and fat quantification in lean tissues using three-point Dixon MR imaging. Pediatr Radiol 2005;35:601-7. doi: 10.1007/s00247-005-1413-y

8. Al-Haddad M, Khashab M, Zyromski N, Pungpapong S, Wallace MB, Scolapio J, et al. Risk factors for hyperechogenic pancreas on endoscopic ultrasound: a casecontrol study. Pancreas 2009;38:672-5. doi: 10.1097/ mpa.0b013e3181a9d5af

9. Uygun A, Kadayifci A, Demirci H, Saglam M, Sakin YS, Ozturk K, et al. The effect of fatty pancreas on serum glucose parameters in patients with non-alcoholic steatohepatitis. Eur J Intern Med 2015;26:37-41. doi: 10.1016/j. ejim.2014.11.007

10. Idilman IS, Tuzun A, Savas B, Elhan AH, Celik A, Idilman R, et al. Quantification of liver, pancreas, kidney, and vertebral body MRI-PDFF in non-alcoholic fatty liver disease. Abdom Imaging 2015;40:1512-9. doi: 10.1007/ s00261-015-0385-0

11. Martinez J, Johnson C, Sanchez-Paya J, De Madaria E, Robles-Diaz G, Perez-Mateo M. Obesity is a definitive risk factor of severity and mortality in acute pancreatitis: an updated meta-analysis. Pancreatology 2006;6:206-9. doi: $10.1159 / 000092104$

12. Papachristou GI, Papachristou DJ, Avula H, Slivka A, Whitcomb DC. Obesity increases the severity of acute pancreatitis: performance of APACHE-O score and correlation with the inflammatory response. Pancreatology 2006;6:279-85. doi: 10.1159/000092689

13. Juge-Aubry CE, Henrichot E, Meier CA. Adipose tissue: a regulator of inflammation. Best Pract Res Clin Endocrinol Metab 2005;19:547-66. doi: 10.1016/j. beem.2005.07.009

14. Greenberg AS, Obin MS. Obesity and the role of adipose tissue in inflammation and metabolism. Am J Clin Nutr 2006;83:461S-5S. doi: 10.1093/ajen/83.2.461S

15. 1Lanaspa MA, Sanchez-Lozada LG, Choi YJ, Cicerchi C, Kanbay M, Roncal-Jimenez CA, et al. Uric acid induces hepatic steatosis by generation of mitochondrial 
oxidative stress: potential role in fructose-dependent and -independent fatty liver. J Biol Chem 2012;287:4073244. doi: 10.1074/jbc.M112.399899

16. Tushuizen ME, Bunck MC, Pouwels PJ, Bontemps S, van Waesberghe JH, Schindhelm RK, et al. Pancreatic fat content and beta-cell function in men with and without type 2 diabetes. Diabetes Care 2007;30:2916-21. doi: $10.2337 / \mathrm{dc} 07-0326$

17. Saisho Y, Butler AE, Meier JJ, Monchamp T, AllenAuerbach M, Rizza RA, et al. Pancreas volumes in humans from birth to age one hundred taking into account sex, obesity, and presence of type- 2 diabetes. Clin Anat 2007;20:933-42. doi: 10.1002/ca.20543

18. Fraulob JC, Ogg-Diamantino R, Fernandes-Santos C, Aguila MB, Mandarim-de-Lacerda CA. A Mouse Model of Metabolic Syndrome: Insulin Resistance, Fatty Liver and Non-Alcoholic Fatty Pancreas Disease (NAFPD) in C57BL/6 Mice Fed a High Fat Diet. J Clin Biochem Nutr 2010;46:212-23. doi: 10.3164/jcbn.09-83

19. Chai J, Liu P, Jin E, Su T, Zhang J, Shi K, et al. MRI chemical shift imaging of the fat content of the pancreas and liver of patients with type 2 diabetes mellitus. Exp Ther Med 2016;11:476-80. doi: 10.3892/etm.2015.2925

20. Dreiling DA, Elsbach P, Schaffner F, Schwartz IL. The effect of restriction of protein and total calories on pancreatic function in obese patients. Gastroenterology 1962;42:686-90.

21. Limanond P, Raman SS, Lassman C, Sayre J, Ghobrial RM, Busuttil RW, et al. Macrovesicular hepatic steatosis in living related liver donors: correlation between CT and histologic findings. Radiology 2004;230:276-80. doi: 10.1148/radiol.2301021176

22. Lee JS, Kim SH, Jun DW, Han JH, Jang EC, Park JY, et al. Clinical implications of fatty pancreas: correlations between fatty pancreas and metabolic syndrome. World J Gastroenterol 2009;15:1869-75. doi: 10.3748/ wjg.15.1869

23. Stamm BH. Incidence and diagnostic significance of minor pathologic changes in the adult pancreas at autopsy: a systematic study of 112 autopsies in patients without known pancreatic disease. Hum Pathol 1984;15:677-83. doi: 10.1016/s0046-8177(84)80294-4

24. Begovatz P, Koliaki C, Weber K, Strassburger K, Nowotny B, Nowotny P, et al. Pancreatic adipose tissue infiltration, parenchymal steatosis and beta cell function in humans. Diabetologia 2015;58:1646-55. doi: 10.1007/ s00125-015-3544-5

25. van der Zijl NJ, Goossens GH, Moors CC, van Raalte DH, Muskiet MH, Pouwels PJ, et al. Ectopic fat storage in the pancreas, liver, and abdominal fat depots: impact on $\beta$-cell function in individuals with impaired glucose metabolism. J Clin Endocrinol Metab 2011;96:459-67. doi: $10.1210 /$ jc. $2010-1722$

26. Heni M, Machann J, Staiger H, Schwenzer NF, Peter A, Schick F, et al. Pancreatic fat is negatively associated with insulin secretion in individuals with impaired fast- ing glucose and/or impaired glucose tolerance: a nuclear magnetic resonance study. Diabetes Metab Res Rev 2010;26:200-5. doi: 10.1002/dmrr.1073

27. Lê KA, Ventura EE, Fisher JQ, Davis JN, Weigensberg MJ, Punyanitya M, et al. Ethnic differences in pancreatic fat accumulation and its relationship with other fat depots and inflammatory markers. Diabetes Care 2011;34:485-90. doi: $10.2337 / \mathrm{dc} 10-0760$

28. Saisho Y, Butler AE, Butler PC. Pancreatic fat content and beta-cell function in men with and without type 2 diabetes: response to Tushuizen et al. Diabetes Care 2008;31:e38; author reply e9. doi: 10.2337/dc08-0044

29. Lingvay I, Esser V, Legendre JL, Price AL, Wertz KM, Adams-Huet B, et al. Noninvasive quantification of pancreatic fat in humans. J Clin Endocrinol Metab 2009;94:4070-6. doi: 10.1210/jc.2009-0584

30. Ou HY, Wang CY, Yang YC, Chen MF, Chang CJ. The association between non-alcoholic fatty pancreas disease and diabetes. PLoS One 2013;8:e62561. doi:10.1371/ journal.pone.0062561

31. Wang D, Yu XP, Xiao WM, Jiao XP, Wu J, Teng DL, et al. Prevalence and clinical characteristics of fatty pancreas in Yangzhou, China: A cross-sectional study. Pancreatology. 2018;18:263-8. doi: 10.1016/j.pan.2018.02.004

32. Sotoudehmanesh R, Tahmasbi A, Sadeghi A, Hosseini H, Mohamadnejad M. The Prevalence of Nonalcoholic Fatty Pancreas by Endoscopic Ultrasonography. Pancreas 2019;48:1220-4. doi: 10.1097/mpa.0000000000001396

33. Joosten LAB, Crişan TO, Bjornstad P, Johnson RJ. Asymptomatic hyperuricaemia: a silent activator of the innate immune system. Nat Rev Rheumatol 2020;16:75-86. doi: 10.1038/s41584-019-0334-3

34. Cabău G, Crișan TO, Klück V, Popp RA, Joosten LAB. Urate-induced immune programming: Consequences for gouty arthritis and hyperuricemia. Immunol Rev 2020;294:92-105. doi: 10.1111/imr.12833

35. American Diabetes A. 2. Classification and Diagnosis of Diabetes: Standards of Medical Care in Diabetes-2020. Diabetes care 2020;43(Suppl 1):S14-S31. doi: 10.2337/ dc20-S002

36. Kim SY, Kim H, Cho JY, Lim S, Cha K, Lee KH, et al. Quantitative assessment of pancreatic fat by using unenhanced CT: pathologic correlation and clinical implications. Radiology 2014;271:104-12. doi: 10.1148/ radiol.13122883 